\title{
Epidemiological and Clinical Features of 200 Hospitalized Patients with Corona Virus Disease 2019 in Yichang, China: A Descriptive Study
}

\author{
Luhuan Yang ${ }^{1 *}$, Yunhong Lei ${ }^{1 *}$, Jinglan Liu ${ }^{1}$, Qiong Liu ${ }^{1}$, Mingwu Li ${ }^{1}$, Xiaojing Zhou ${ }^{1}$, Chuangjun \\ $\mathrm{Hu}^{1}$, Zifeng $\mathrm{Li}^{1}$, Rong Zhang ${ }^{1}$ and Jun Yang ${ }^{2}$ \\ ${ }^{1}$ Department of Emergency and Critical Care Medicine, The First College of Clinical Medical Science, Three Gorges University/ \\ Yichang Central People's Hospital, China
}

${ }^{2}$ Department of Cardiovascular Medicine, The First College of Clinical Medical Science, Three Gorges University/Yichang Central People's Hospital, China

*Corresponding author: LuhuanYang, Department of Emergency and Critical Care Medicine, The First College of Clinical Medical Science, Three Gorges University/Yichang Central People’s Hospital, Yichang City, Hubei Province 443003, China

Yunhong Lei, Department of Emergency and Critical Care Medicine, The First College of Clinical Medical Science, Three

Gorges University/Yichang Central People’s Hospital, Yichang City, Hubei Province 443003, China

\begin{abstract}
ARTICLE INFO
Received: 㓞 April 08, 2020

Published: 幽 April 22, 2020

Citation: Luhuan Yang, Yunhong Lei, Jinglan Liu, Qiong Liu, Mingwu Li, et al. Epidemiological and Clinical Features of 200 Hospitalized Patients with Corona Virus Disease 2019 in Yichang, China: A Descriptive Study. Biomed J Sci \& Tech Res 27(1)-2020. BJSTR. MS.ID.004459.
\end{abstract}

Abbreviations: CT: Computed Tomographic, MERS: Middle Eastern Respiratory Syndrome, SARS: Severe Acute Respiratory Syndrome, CDC: Center for Disease Control and Prevention

\section{ABSTRACT}

Recently, the outbreak of Corona Virus Disease 2019 (COVID-19) originating in Wuhan has rapidly spread across China and beyond, with especially severe epidemic in cities around Wuhan. We report the epidemiological and clinical futures of the 200 patients infected with COVID-19 in Yichang, Hubei Province, China. A total of 200 patients confirmed with COVID-19 in a designated hospital in Yichang from Jan 30 to Feb 8,2020 were investigated retrospectively. The epidemiological data, demographic data, comorbidities and clinical manifestations, laboratory tests, chest CT scans, treatment and clinical outcomes were collected. The data between patients admitted to the intensive care unit (ICU) and those not in the intensive care unit were compared. The patients were followed up until Feb 26, 2020.The Corona Virus Disease 2019 (COVID-19) infection was of clustering onset, and can cause severe respiratory disease and even death, especially for elderly patients with chronic disease. The mortality of ICU patients confirmed with COVID-19 was considerably high. The lymphocytes, especially T lymphocytes might be the main target of Corona Virus Disease 2019 (COVID-19) and related to the severity and mortality of disease, and the cytokine storm may be associated with the worsening of the disease

Keywords: Pneumonia; Epidemiology; Clinical Features; Hospitalized Patients; 2019$\mathrm{nCoV}$

\section{Introduction}

In December 2019, a new pneumonia case of unknown etiology emerged and began to widely spread in Wuhan, Hubei Province, China. Most of the patients were epidemiologically linked to the Huanan Seafood Wholesale Market, indicating animal-to-human disease transmission mode, but soon there was considerable evidence to confirm the human-to-human transmission [1,2]. Within two weeks after the outbreak, the Chinese Center for Disease Control and Prevention (CDC) isolated samples from lower respiratory tract for deep sequencing analysis, suggesting a novel coronavirus, which was officially named SARS-CoV-2 by WHO on Feb 11, 2020. Since the SARS-CoV-2 has typical characteristics of the coronavirus family, it is currently classified in the lineage B beta coronaviruses that also include Severe Acute Respiratory Syndrome (SARS) and Middle Eastern Respiratory Syndrome (MERS) [3-6]. Although the source of the SARS-CoV-2 is still under investigation, genome sequencing and phylogenetic analysis proved that the sequence of RNA genome of the virus is similar to bat coronaviruses, indicating the bats maybe the primary source [7]. 
The disease caused by the SARS-CoV- 2 was officially named Corona Virus Disease 2019 (COVID-19) by WHO [8]. Previous studies showed that the clinical manifestations of patients with COVID-19 in Wuhan mainly included fever, chill, cough, difficulty in breathing, muscle soreness, fatigue, as well as complications such as acute respiratory distress syndrome (ARDS), acute kidney injury, and acute cardiac injury, etc [9]. Laboratory tests showed that the leukocytes were normal or decreased, and/or the lymphocytes decreased. And the chest imaging revealed typical features of viral pneumonia [10]. Wang et al reported that among the 138 investigated patients, 36 received ICU care, with the mortality of $4.3 \%$. It was found that the COVID-19 was of clustering onset, and the older men with comorbidities were more likely to develop into critically ill patients [11]. Although the government adopted a series of measures to respond to this major public health emergency, such as prohibiting from leaving or coming into Wuhan and group activities, in the following dozens of days, a large cluster of the pneumonia rapidly spread throughout China and beyond. And the epidemic was especially severe in cities around Wuhan in Hubei Province. As of Feb 26, 2020, there were 78630 confirmed COVID-19 cases, 2358 suspected cases, 32531 cured cases, and 2747 deaths in China, of which 65596 were confirmed cases in Hubei Province and 929 were confirmed cases in Yichang City, which owns huge economic development potential in Hubei Province, second only to Wuhan[12,13].

So far, there have been several studies that have summarized and analyzed the epidemiological and clinical features of pneumonia caused by SARS-CoV-2 in Wuhan [14-16]. However, the information on the epidemiological and clinical features of COVID-19 in other areas is scarce. The main purpose of this study was to comprehensively analyze and compare the epidemiological, clinical, laboratory, radiological, treatment, and outcome data of confirmed patients with COVID-19 admitted in a designated hospital in Yichang, Hubei Province, China. We hope our findings can provide some references for understanding the epidemics and clinical characteristics of this novel coronavirus outside Wuhan.

\section{Materials and Methods}

\section{Sample Collection}

200 patients with confirmed COVID-19 were recruited from Jan 30 to Feb 08, 2020 at Yichang Central People's Hospital, a designated hospital in Yichang, Hubei Province, China. Patients throughout Yichang City were centrally admitted to the hospital without selectivity. All the enrolled COVID-19 patients in this study were diagnosed according to WHO interim guidance. The study was approved by the Ethics Committee of Yichang Central People's Hospital and written informed consent was obtained from the enrolled patients.

\section{Procedures}

The epidemiological, clinical, laboratory, treatment, and outcome data of the patients were obtained from electronic medical records. All the data were reviewed by two physicians (LH Yang and R Zhang).The information included demographic data, family clustering ( $\geq 2$ infected family member),exposure history (living in or visiting Wuhan or contact with people from Wuhan $\leq 14$ days before infection), comorbidities, clinical manifestations (symptoms and signs), laboratory tests, chest Computed Tomographic (CT) scans, treatment (ie, medical treatment, respiratory support, renal replacement therapy), and outcomes (complications, including death). Throat-swab samples from the upper respiratory tract were collected during hospitalization. SARS-COV-2 was detected by real-time polymerase chain reaction (RT-PCR) following the recommended protocol. Infection was confirmed when there were at least 2 positive results.

\section{Outcomes}

We described and summarized demographic data, family clustering, exposure history, potential comorbidities, clinical manifestations, laboratory tests, chest CT scans, treatment measures, and prognosis.

\section{Statistical Analysis}

All statistical analyses were performed using SPSS20.0 version software. Continuous variables were represented as mean, median, and Interquartile Range (IQR) values. Independent group t-test was used to compare the means of continuous variables when the data were normally distributed. Categorical variables were represented as frequency and percentage. The Mann-Whitney test was used when the data were non-normally distributed. Chi-square test was used to compare proportions of categorical variables, although Fisher's exact test was used in cases where data was limited. A twosided $\alpha$ of less than $0 \cdot 05$ was considered statistically significant.

\section{Result}

A total of 200 patients with laboratory-confirmed COVID19 were enrolled in the study. Among them, 98(49.0\%) were male and $102(51.0 \%)$ were female, with the mean age of 55 years (SD 17.1 years). Three children and two pregnant women were infected. Of the 200 patients, 29 (14.5\%) were admitted to the ICU because of the requirement of high-level oxygen support measures or the development of organ dysfunction, and the remaining 171 (85.5\%) were admitted to isolation wards. The age of ICU patients (mean age 71 years, SD13.4) was older than the non-ICU patients (mean age 52 years, SD 16.2, $\mathrm{P}=0.000$ ). About two thirds of the patients came from Xiling District of Yichang City. Of these patients,24(12.0\%) had a history of residing in or visiting Wuhan within 2 weeks before infection, $89(44.5 \%)$ had an intensive contact with visitors from Wuhan or confirmed COVID-19 patients, and the remaining $87(43.5 \%)$ had no linkage to Wuhan or contact history. Familial clustering was found in 34 patients, accounting for $17 \%$. Among the 200 patients, $65(32.5 \%)$ suffered from 1 or more comorbidities, with hypertension (45[22.5\%]), diabetes (21[10.5\%]) and chronic heart disease (11[5.5\%]) as the top three common coexisting conditions (Table 1). 
Table 1: Demographics, Epidemigical and Clinical Characteristics of Patients with Corona Virus Disease 2019 (COVID-19).

\begin{tabular}{|c|c|c|c|c|}
\hline \multicolumn{2}{|l|}{ Total $(n=200)$} & \multirow{2}{*}{$\begin{array}{c}\text { ICU (n=29) } \\
71(13.4)\end{array}$} & \multirow{2}{*}{$\frac{\text { Non-ICU }(\mathbf{n}=\mathbf{1 7 1})}{52(16.2)}$} & \multirow{2}{*}{$\begin{array}{c}\text { P value } \\
0\end{array}$} \\
\hline Age year & $55(17.1)$ & & & \\
\hline \multicolumn{5}{|c|}{ Gender } \\
\hline Male & $98(49 \%)$ & $16(55.2 \%)$ & $82(48.0 \%)$ & 0.47 \\
\hline Female & $102(51 \%)$ & $13(44.8 \%)$ & $89(52.0 \%)$ & \\
\hline \multicolumn{5}{|l|}{ District } \\
\hline XilingDistirct & $130(65 \%)$ & $21(72.4 \%)$ & $109(63.8 \%)$ & 0.37 \\
\hline Non-Xiling District & $70(35 \%)$ & $8(27.6 \%)$ & $62(36.3 \%)$ & \\
\hline \multicolumn{5}{|c|}{ Epidemiological History Within 2 Weeks Before Infection } \\
\hline Wuhan residence or travelling & $24(12 \%)$ & $1(3.4 \%)$ & $23(13.4 \%)$ & 0.01 \\
\hline Close contact history & $89(44.5 \%)$ & $8(27.6 \%)$ & $81(47.4 \%)$ & \\
\hline Others & $87(43.5 \%)$ & $20(69.0 \%)$ & $67(39.2 \%)$ & \\
\hline Familial clustering & $34(17 \%)$ & $4(13.8 \%)$ & $30(17.5 \%)$ & \\
\hline Comorbidities & $65(32.5 \%)$ & $13(44.8 \%)$ & $52(30.4 \%)$ & 0.13 \\
\hline Hypertension & $45(22.5 \%)$ & $9(31.0 \%)$ & $36(21.1 \%)$ & 0.23 \\
\hline Chronic lung disease & $7(3.5 \%)$ & $4(13.8 \%)$ & $3(1.8 \%)$ & 0.01 \\
\hline Diabetes & $21(10.5 \%)$ & $4(13.8 \%)$ & $17(9.94 \%)$ & 0.53 \\
\hline Chronic heart disease & $11(5.5 \%)$ & $1(3.4 \%)$ & $10(5.8 \%)$ & 0.6 \\
\hline Chronic kidney disease & $3(1.5 \%)$ & $2(6.9 \%)$ & $1(0.6 \%)$ & 0.01 \\
\hline Chronic liver disease & $2(1 \%)$ & 0 & $2(1.2 \%)$ & 0.56 \\
\hline Malignancy & $4(2 \%)$ & $1(3.4 \%)$ & $3(1.8 \%)$ & 0.55 \\
\hline Smoking history & $9(4.5 \%)$ & $1(3.4 \%)$ & $8(4.7 \%)$ & 0.77 \\
\hline \multicolumn{5}{|c|}{ Signs and Symptoms } \\
\hline Fever, ${ }^{\circ} \mathrm{C}$ & $38.0(37.5-38.5)$ & $38.1(38.0-38.9)$ & $38.0(37.5-38.5)$ & 0.06 \\
\hline$\geq 37.3^{\circ} \mathrm{C}$ & $171(85.5 \%)$ & $25(86.2 \%)$ & $146(85.4 \%)$ & 0.9 \\
\hline$<37.3^{\circ} \mathrm{C}$ & $29(14.5 \%)$ & $4(13.8 \%)$ & $25(14.6 \%)$ & 0.9 \\
\hline Cough & $116(58.0 \%)$ & $16(55.2 \%)$ & $100(58.5 \%)$ & 0.74 \\
\hline Fatigue & $64(32.0 \%)$ & $13(44.8 \%)$ & $51(29.8 \%)$ & 0.23 \\
\hline Chills or rigors & $34(17.0 \%)$ & $8(27.6 \%)$ & $26(15.2 \%)$ & 0.1 \\
\hline Myalgia or malaise & $44(22.0 \%)$ & $5(17.2 \%)$ & $39(22.8 \%)$ & 0.5 \\
\hline Sore throat & $26(13.0 \%)$ & $1(3.4 \%)$ & $25(14.6 \%)$ & 0.1 \\
\hline Dyspnea & $29(14.5 \%)$ & $22(75.9 \%)$ & $7(4.1 \%)$ & 0.01 \\
\hline Headache & $27(13.5 \%)$ & $2(6.9 \%)$ & $25(14.6 \%)$ & 0.26 \\
\hline Diarrhea & $14(7 \%)$ & $3(10.3 \%)$ & $11(6.4 \%)$ & 0.54 \\
\hline Nausea and vomiting & $4(2 \%)$ & $2(6.9 \%)$ & $2(1.2 \%)$ & 0.04 \\
\hline Duration from illness onset to admission, $\mathrm{d}$ & $5.0(2.25-7.0)$ & $4.0(3.0-8.5)$ & $5.0(2.0-2.0)$ & 0.73 \\
\hline
\end{tabular}

Note: Data are mean (SD), median (IQR), n (\%), P values comparing patients with ICU and non-ICU are from t-test, $\chi^{2}$ test, Fisher's Exact Test, or Mann-Whitney U test. NCP=Novel Coronavirus Pneumonia. ICU=Intensive Care Unit.

Most patients had fever (171[85.5\%]) and cough (116[58.0\%]) on admission. And some patients had fatigue (64[32\%]), myalgia and malaise (44[22\%]), dyspnea (29[14.5\%]), chills or rigors (34[17\%]), headache $(27[13.5 \%])$ and sore throat $(26[13 \%])$. Other symptoms included diarrhea (14[7\%]), nausea and vomiting (4[2\%]). Compared with the patients admitted to the isolated wards, patients who received ICU care were more likely to show dyspnea, nausea and vomiting. In addition, 6 patients with nonICU care were asymptotic, all of whom found lung imaging changes after having epidemiological exposure history. The median time from illness onset to first admission was 5 days (IQR 2.25-7.0). On admission, the leucocytes of most patients were below or within the normal range. And most patients had lymphopenia, with the median level of $0.91 \times 109 / \mathrm{L}(\mathrm{IQR}, 0.69-1.22)$.There were significant differences in the median value of lymphocytes and the proportion of lymphopenia between patients with ICU care and those with non-ICU care $(0.73 \times 109 / \mathrm{L}$ [IQR,0.56-0.89]vs $0.94 \times 109 / \mathrm{L}$ [IQR, $0.73-1.26$ ], $\mathrm{P}=0.000 ; 25$ [86.2\%] vs 112 [65.5\%], $\mathrm{P}=0.026)$. The C-reactive protein and D-dimer were higher in ICU patients than non-ICU patients median C-reactive protein level $68.8 \mathrm{mg} / \mathrm{L}$ [IQR, 
53.47-108.25] vs $18.7 \mathrm{mg} / \mathrm{L} \quad$ [IQR,6.3-37.9],P=0.000; median D-dimer level $1.1 \mathrm{mg} / \mathrm{L}[\mathrm{IQR}, 0.6-1.8]$ vs $0.5 \mathrm{mg} / \mathrm{L}[0.3-0.7], \mathrm{P}=0.000$.

The incidences of ALT and AST above the normal range in ICU patients were higher than those in non-ICU patients $(41.4 \% \mathrm{vs}$ 18.7\%, $\mathrm{P}=0.006 ; 58.6 \%$ vs 33.3\%, $\mathrm{P}=0.009)$. 57(28.5\%) patients had different degrees of kidney dysfunction, with serum creatinine above the normal range. 77 (38.5\%) patients showed an elevation of lactate dehydrogenase, of whom 22 belonged to the 29 ICU-patients (81.5\%). The Procalcitonin was increased in 25 (86.2\%) of ICU patients, higher than the non-ICU patients $(23[13.5 \%], \mathrm{P}<0.001)$. According to chest CT on admission,176 (86\%) patients had bilateral involvement (Table 2). Many of the patients presented with complications, including $32(16 \%)$ with acute respiratory distress syndrome (ARDS), $10(\%)$ with acute cardiac injury, 24(12\%) with acute renal injury,12(6.0\%) with secondary infection, and $4(2 \%)$ with shock (Table 3). And it was found that the complications were more common in the ICU patients than in the non-ICU patients.199(99.5\%) of the 200 patients were treated with antiviral therapy (Abidol, Oseltamivir, Lopinavir/ritonavir), and 141(70.5\%) received antibiotic treatment (Moxifloxacin, Ceftriaxone). More than half of the patients (112[56\%]) received corticosteroid therapy. 2 patients $(2[1 \%])$ were treated with continuous renal replacement therapy (CRRT). All patients received oxygen support on admission. Most patients (24[82.8\%]) in the ICU received high flow oxygen or noninvasive ventilation. 14 patients $(48.3 \%)$ required invasive mechanical ventilation to relieve hypoxemia.

Table 2: Liboratory Findings of Patients with Corona Virus Disease 2019 (COVID-19).

\begin{tabular}{|c|c|c|c|c|}
\hline \multicolumn{2}{|c|}{ Patients $(n=200)$} & \multirow{2}{*}{$\begin{array}{c}\text { ICU(n=29) } \\
5.76(4.06-7.82)\end{array}$} & \multirow{2}{*}{$\begin{array}{c}\text { Non-ICU (n=171) } \\
4.37(3.47-5.48)\end{array}$} & \multirow{2}{*}{$\begin{array}{c}\text { P Value } \\
0.01\end{array}$} \\
\hline Leucocytes, $\times 10^{9} / \mathrm{L}$ & $4.4(3.5-5.7)$ & & & \\
\hline$<3.5$ & $45(22.5 \%)$ & $2(6.9 \%)$ & $43(25.1 \%)$ & 0.04 \\
\hline $3.5 \sim 9.5$ & $149(74.5 \%)$ & $25(86.2 \%)$ & $124(72.5 \%)$ & 0.11 \\
\hline$>9.5$ & $6(3 \%)$ & $2(6.9 \%)$ & $4(2.3 \%)$ & 0.18 \\
\hline Neutrophils, $\times 10^{9} / \mathrm{L}$ & $2.92(2.15-4.07)$ & $4.8(2.8-6.39)$ & $2.78(2.1-3.79)$ & 0 \\
\hline Lymphocytes, $\times 10^{9} / \mathrm{L}$ & $0.91(0.69-1.22)$ & $0.73(0.56-0.89)$ & $0.94(0.73-1.26)$ & 0 \\
\hline$<1.1$ & $137(68.5 \%)$ & $25(86.2 \%)$ & $112(65.5 \%)$ & 0.02 \\
\hline Haemoglobin, g/L & $132.0(17.5)$ & $123.72(19.9)$ & $133.40(16.7)$ & 0 \\
\hline Platelets, $\times 10^{9} / \mathrm{L}$ & $154.0(124.2-189.0)$ & $145(120.5-177)$ & $155(125-192)$ & 0.23 \\
\hline$<125$ & $50(25 \%)$ & $9(31.0 \%)$ & $41(24.0 \%)$ & 0.41 \\
\hline Activated partial thromboplastin time, s & $34.0(30.3-37.3)$ & $36.7(34.0-41.0)$ & $33.3(30.1-36.2)$ & 0 \\
\hline Prothrombin time, s & $11.0(10.5-11.5)$ & $11.4(10.6-12.0)$ & $11(10.5-11.4)$ & 0.02 \\
\hline$<10.5$ & $42 / 187(22.5 \%)$ & $5 / 29(17.2 \%)$ & $37 / 158(23.4 \%)$ & 0.55 \\
\hline D-dimer, ng/mL & $532(314-768)$ & $1100(639-1824)$ & $497(306-746)$ & 0 \\
\hline$>500$ & $119 / 190(62.6 \%)$ & $25 / 28(89.7 \%)$ & $94 / 162(58.0 \%)$ & 0.15 \\
\hline Albumin, g/L & $37.88(34.61-40.22)$ & $32.49(26.05-34.96)$ & $38.32(35.48-40.70)$ & 0 \\
\hline$<40$ & $144(72 \%)$ & $28(96.6 \%)$ & $116(67.8 \%)$ & 0 \\
\hline Alanine aminotransferase, U/L & $26(19-75)$ & $30(20.5-76.5)$ & $26(19-36)$ & 0.04 \\
\hline$>40$ & $44(22 \%)$ & $12(41.4 \%)$ & $32(18.7 \%)$ & 0 \\
\hline Aspartate aminotransferase, U/L & $32(26-39.75)$ & $41(33.5-64.5)$ & $31(25-39)$ & 0 \\
\hline$>35$ & $74(37 \%)$ & $17(58.6 \%)$ & $57(33.3 \%)$ & 0 \\
\hline Total bilirubin, mmol/L & $12.46(10.5725-16.085)$ & $13.18(10.155-18.285)$ & $12.45(10.61-15.92)$ & 0.58 \\
\hline Potassium, mmol/L & $3.73(0.42)$ & $3.90(0.54)$ & $3.7(0.39)$ & 0.06 \\
\hline Sodium, mmol/L & $137.7(135.525-139.6)$ & $136.1(133.25-139.3)$ & 137.8(136.2-139.6) & 0.05 \\
\hline Serum creatinine, $\mu \mathrm{mol} / \mathrm{L}$ & $64(52.5-83.1)$ & $85.6(65.875-23.275)$ & $61.8(50.075-81.45)$ & 0 \\
\hline$>81$ & $57(28.5 \%)$ & $14(48.3 \%)$ & $43(25.1 \%)$ & 0.01 \\
\hline
\end{tabular}




\begin{tabular}{|c|c|c|c|c|}
\hline Creatine kinase,IU/L & $92(61.25-151.75)$ & $113(72-192.5)$ & $88(61-144)$ & 0.09 \\
\hline$>200$ & $31 / 189(16.2 \%)$ & $6 / 27(22.2 \%)$ & $25 / 162(15.4 \%)$ & 0.45 \\
\hline Lactate dehydrogenase, U/L & $229(187-298)$ & $342(260.5-468.5)$ & $217(183-274)$ & 0 \\
\hline$>250$ & 74/189 (38.5\%) & $22 / 27(81.5 \%)$ & $52 / 162(32.1 \%)$ & 0 \\
\hline CKMB, IU/L & $11(9-14)$ & $12.5(10-19)$ & $11(9-14)$ & 0.03 \\
\hline$>25$ & $5 / 189(2.6 \%)$ & $3 / 27(11.1 \%)$ & $2 / 162(1.2 \%)$ & 0 \\
\hline Procalcitonin $>0.05 \mathrm{ng} / \mathrm{Ml}$ & $44 / 182(24.2 \%)$ & $23 / 27(85.2 \%)$ & $21 / 155(13.5 \%)$ & 0 \\
\hline C-reactive protein, $\mathrm{mg} / \mathrm{L}$ & $22.95(7.45-54.085)$ & $68.8(53.47-108.25)$ & $18.7(6.3-37.9)$ & 0 \\
\hline$>10$ & $141 / 200(70.5 \%)$ & $29 / 29(100 \%)$ & $112 / 171(65.5 \%)$ & 0 \\
\hline Bilateral involvement of chest CT & $172 / 200(86 \%)$ & $28 / 29(96.6 \%)$ & $144 / 171(84.2 \%)$ & 0.07 \\
\hline
\end{tabular}

Note: Data are median (IQR), mean (SD), $\mathrm{n}(\%)$, or $\mathrm{n} / \mathrm{N}(\%)$, where $\mathrm{N}$ is the total number of patients with available data.P values comparing patients with ICU and non-ICU are from $t$-test, $\chi^{2}$ test, Fisher's exact test, or Mann-Whitney U test.NCP=Novel Coronavirus Pneumonia. ICU=Intensive Care Unit.

Table 3: Complications, Treatments, and Prognosis of Patients with Corona Virus Disease 2019 (COVID-19).

\begin{tabular}{|c|c|c|c|c|}
\hline Patients $(n=200)$ & & $\operatorname{ICU}(n=29)$ & Non-ICU(n=171) & P Value \\
\hline \multicolumn{5}{|c|}{ Complications } \\
\hline ARDS & $32(16 \%)$ & $21(72.4 \%)$ & $11(6.4 \%)$ & 0 \\
\hline Acute cardiac injury & $20(10 \%)$ & $15(51.7 \%)$ & $5(2.9 \%)$ & 0 \\
\hline Acute kidney injury & $24(12 \%)$ & $12(41.3 \%)$ & $12(7.0 \%)$ & 0 \\
\hline Secondary infection & $12(6.0)$ & $5(17.2 \%)$ & $7(4.1 \%)$ & 0 \\
\hline Shock & $4(2 \%)$ & $4(13.8 \%)$ & 0 & 0 \\
\hline \multicolumn{5}{|c|}{ Treatment } \\
\hline Antiviral therapy & $199(99.5 \%)$ & $28(96.6 \%)$ & $171(100 \%)$ & 0.01 \\
\hline Antibiotic therapy & $141(70.5 \%)$ & $29(100 \%)$ & $112(65.5 \%)$ & 0 \\
\hline Use of corticosteroid & $112(56 \%)$ & $20(69.0 \%)$ & $92(53.8 \%)$ & 0.12 \\
\hline CRRT & $2(1 \%)$ & $2(6.9 \%)$ & 0 & 0 \\
\hline \multicolumn{5}{|c|}{ Oxygen Support } \\
\hline Nasal cannula & $158(79 \%)$ & $5(17.2 \%)$ & $153(89.5 \%)$ & 0 \\
\hline $\begin{array}{l}\text { Non-invasive ventilation or } \\
\text { high-flow nasal cannula }\end{array}$ & $35(17.5 \%)$ & $24(82.8 \%)$ & $11(6.4 \%)$ & 0 \\
\hline $\begin{array}{l}\text { Invasive mechanical } \\
\text { ventilation }\end{array}$ & $16(8.0 \%)$ & $14(48.3 \%)$ & $2(1.2 \%)$ & 0 \\
\hline \multicolumn{5}{|c|}{ Prognosis } \\
\hline Hospitalization & $143(71.5 \%)$ & $11(37.9 \%)$ & $132(77.2 \%)$ & 0 \\
\hline Discharge & $42(21 \%)$ & $4(13.8 \%)$ & $38(22.2 \%)$ & 0.94 \\
\hline Death & $15(7.5 \%)$ & $14(48.3 \%)$ & $1(0.6 \%)$ & 0 \\
\hline
\end{tabular}

In the non-ICU wards, high flow oxygen or noninvasive ventilation was required in 11 patients (9.9\%), two of whom received invasive mechanical ventilation with the worsening of the disease. As of Feb26, 2020, 42 (21\%) of 200 patients had been discharged including two children and 16(8.0\%) patients had died. Of the 29patients in the ICU, 12were still hospitalized, 3 had been discharged and15 had died. Through analyzing and tracking laboratory results of the patients who had died, we found that the neutrophils, PCT, IL-6 and CRP were $14.2 \times 109 / \mathrm{L}(\mathrm{SD} 8.4), 4.49 \mathrm{ng} /$ $\mathrm{ml}$ (IQR 1.57-25.8), $248.85 \mathrm{pg} / \mathrm{ml}$ (IQR,77.54-1671.3) and 105.7 $\mathrm{mg} / \mathrm{L}(\mathrm{IQR}$ 82.7-220.1) before they died, which were significantly higher than the normal range. The main imaging findings included bilateral mottling and ground glass opacity, multiple lobular or subsegmental areas of consolidation (Figure1). And all the 200 cases of SARS-CoV-2 infection were confirmed by RT-PCR. 


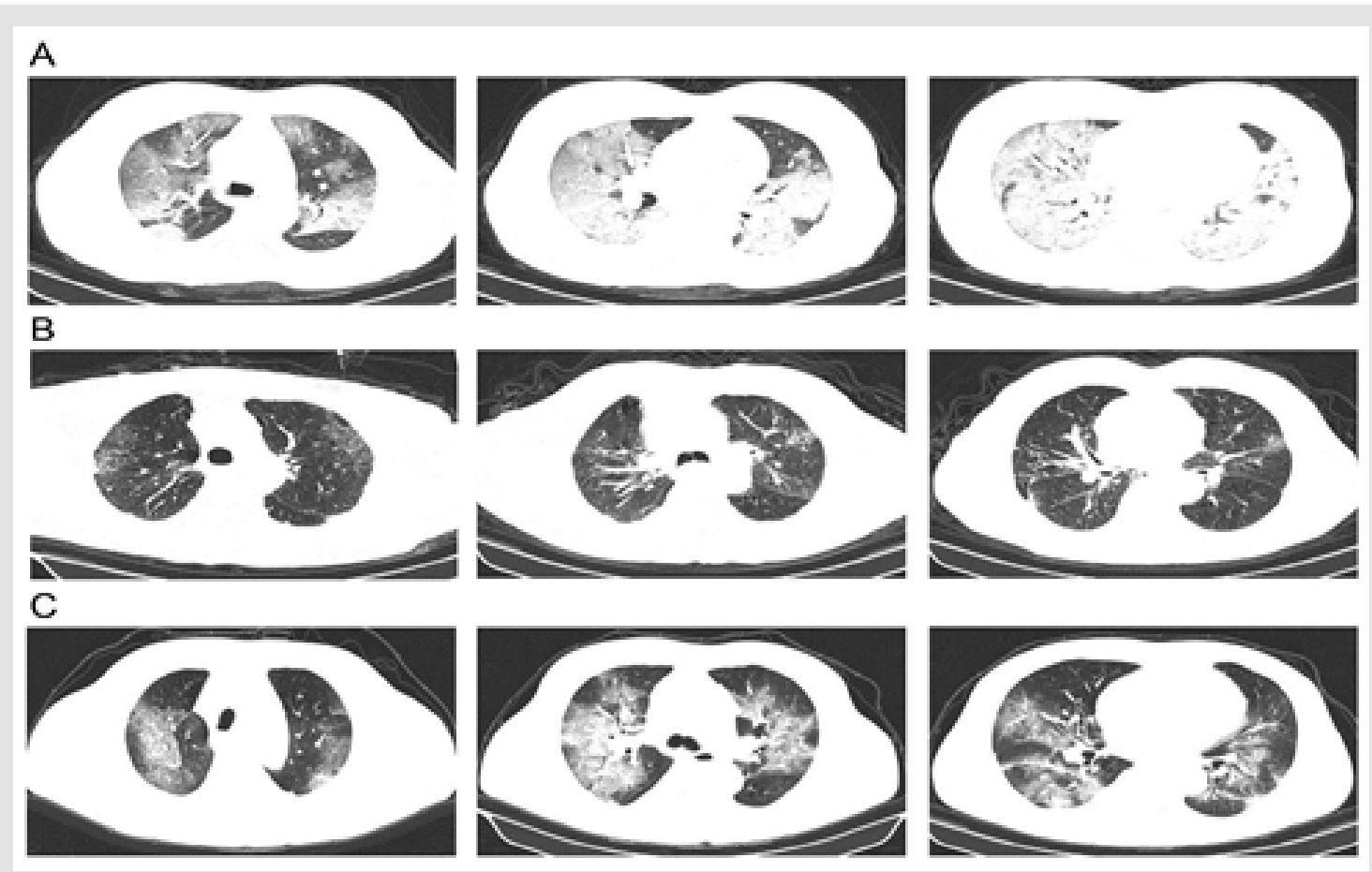

Figure 1: Chest Computed Tomographic Images

A. Chest CT of a 51-year-old female taken on Feb 06, 2020 showed diffuse patchy shadows and ground glass opacity, with lobular and subsegmental consolidation.

B. Chest CT images from an 83-year-old male who had COPD showed multiple mottling and ground-glass opacity on Feb $1,2020$.

C. However, the lesions on both lungs were larger with patchy and nodular increased-density shadow on Feb 6, 2020.

\section{Discussion}

Here in, we reported a total of 200 patients with confirmedCOVID-19. The 200 patients were admitted to the designated hospital in just 10 days from Jan 30, 2020 to Feb 8,2020, indicating the outbreak of the COVID-19 in Yichang, China. Meanwhile, the local government actively adopted public health outbreak response tactics, including quarantine, isolation, school closure, social distancing, and community containment, etc. As of Feb 23, 2020 in Yichang, 924 caseswereconfirmed,304 cases were cured, and 29 cases were dead, with the case fatality rate of $3.14 \%$. While according to the latest study by Xb Yang and his colleagues, the case fatality rate of critically ill patients with COVID-19 at 28 days was $61.5 \%$, which was very considerable. Similarly, during our 28-day follow-up after admission in our study, 15 of the 29 ICU patients had died, and the case fatality rate in the ICU was as high as $51.7 \%$.Our study also found that the population was generally susceptible to the virus, and the older patients with comorbid conditions usually developed into critically ill cases with many complications and required ICU admission.

As mentioned in the previous section, many patients came from Xiling District of Yichang City, which may be related to the fact that some residents of the area worked in Wuhan. Through the epidemiological survey, only 24(12.0\%) were founded to have a history of Wuhan residence or travel within 14 days before onset of illness. Almost half of the patients had no linkage to Wuhan or contact history. This suggests the human-to-human transmission and highly contagiousness of the SARS-COV-2. At present, the main transmission routes of SARS-COV-2 are proved to be droplet transmission and contact transmission, with the possibility of aerosol transmission in prolonged exposure to high concentrations of aerosol in a relatively closed environment. Finding out the transmission routes can help to prevent the spread of the SARSCOV-2 more effectively [17]. Similar to those infected with beta coronaviruses such as SARS-CoV and MERS-CoV, most patients with SARS-CoV-2 infection presented with fever, cough, fatigue, dyspnoea, and bilateral ground-glass opacities and patchy shadows on chest computed tomography. Sore throat, headache, diarrhea, nausea and vomiting occurred in a few patients infected with SARSCoV-2 [18]. In addition, 6 people were asymptomatic. As for the laboratory tests, the lymphocytes of most patients were below the normal range, and the lymphocytes in ICU patients were less than those in non-ICU patients. This result suggests that lymphocytes, especially $\mathrm{T}$ lymphocytes might be the main target of SARS-CoV-2 and related to the severity and mortality of disease. $\mathrm{Z} \mathrm{Xu}$ and his colleagues showed the T cells were excessively activated while the 
counts were substantially reduced by autopsy of a patient with COVID-19 [19]. Moreover, our study also found that the neutrophils, PCT, IL- 6 and CRP of the 14 patients who had died were significantly higher than the normal range, suggesting that the cytokine storm maybe associated with disease. Virus particles penetrate the respiratory mucosa and activate lymphocytes, then induces forms a cytokine storm, which causes severe immune damage to the lungs and other organs $[20,21]$. However, the specific pathophysiology of COVID-19remains to be further explored.

At present, some effective treatment methods for COVID-19 have been summarized based on clinical practice [22-24]. The antiviral drugs for COVID-19 in clinic curently mainly include $\alpha$ interferon aerosol inhalation, Lopinavir / ritonavir, Ribavirin, Chloroquine phosphate and Abidol [25]. And the antibiotics should be used cautiously [26]. If the patient has dyspnea and chest imaging progress, glucocorticoids can be used within a short period of time (3 to 5 days) with the dose not exceeding $2 \mathrm{mg} /$ $\mathrm{kg} /$ day of methylprednisolone [23]. Other treatments include respiratory support, traditional Chinese medicine treatment, the plasma treatment of rehabilitation patients, extracorporeal blood purification technologies such as plasma exchange, adsorption, perfusion, and hemofiltration. And a vaccine against SARS-CoV-2 is being under development.

There are still some limitations in this study. First of all, this study only included patients admitted to Yichang Central People's Hospital, which might not fully represent all the patients in the city. Multi-center collaborative studies with larger sample size in the future are required. Secondly, throat swab specimens were used to diagnose COVID-19 by RT-PCR. However, specimens collected from the upper respiratory tract may lead to false negatives, thus leading to missed diagnosis and pseudo-cure cases. The viral load and viral antigen in blood can be detected to provide better assessment of the condition. Thirdly, many patients are still hospitalized at the time of manuscript submission, and the outcomes at present may not fully reflect the prognosis of all patients with COVID-19.

\section{Conclusion}

In conclusion, of the 200 patients infected with COVID-19in Yichang, China, $14.5 \%$ of patients were admitted to the ICU, who were mainly older patients with comorbidities and ARDS. And the mortality of confirmed patients in the ICU was high.

\section{Acknowledgment}

We thank all participating patients and their families, as well as staffs of all the institutions involved in this study.

\section{Contributors}

Luhuan Yang and Yunhong Leicontributed equally. Luhuan Yang had the original idea, designed the study with Yunhong Lei, and drafted the manuscript, Luhuan Yang Rong Zhang,Jinglan Liu and Qiong Liu collected and summarized the epidemiological and clinical data, Jun Yang and Yunhong Lei revised the final manuscript, Mingwu Li,Xiaojing Zhou,Chuangjun $\mathrm{Hu}$ and Zifeng Li retrieved the document about the virus.

\section{Declaration of Interests}

We declare no competing interests.

\section{ORCID}

Luhuan Yang https://orcid.org/0000-0002-8868-9193

Yunhong Lei https://orcid.org/0000-0003-4838-2709

\section{References}

1. Michaels MG, La Hoz RM, Danziger Isakov L, Blumberg EA, Kumar, et al. (2020) Coronavirus Disease 2019: Implications of Emerging Infections for Transplantation. Am J Transplant.

2. Zhao S, Lin Q, Ran J, Musa SS, Yang G, et al. (2020) Preliminary estimation of the basic reproduction number of novel coronavirus (2019-nCoV) in China, from 2019 to 2020: A data-driven analysis in the early phase of the outbreak. Int J Infect Dis 92: 214-217.

3. Kazanji N, Klein RE, Lohani S, Mertens AN, Le J (2016) A case of hypermucoviscous Klebsiella pneumoniae liver abscess syndrome in an Iraqi male. QJM 109: 493-494.

4. Takahashi Y, Fujii K, Yoshida A, Morisaki H, Kohno Y, et al. (2013) Artery tortuosity syndrome exhibiting early-onset emphysema with novel compound heterozygous SLC2A10 mutations. Am J Med Genet A 161A: 856-859.

5. Assiri A, Al Tawfiq JA, Al Rabeeah AA, Al Rabiah FA, Al Hajjar S, et al. (2013) Epidemiological, demographic, and clinical characteristics of 47 cases of Middle East respiratory syndrome coronavirus disease from Saudi Arabia: a descriptive study. Lancet Infect Dis 13: 752-761.

6. Al-Tawfiq JA, Zumla A, Gautret P, Gray GC, Hui DS, et al. (2014) Surveillance for emerging respiratory viruses. Lancet Infect Dis 14: 992-1000.

7. Zhou P, Yang XL, Wang XG, Hu B, Zhang L, et al. (2020) A pneumonia outbreak associated with a new coronavirus of probable bat origin. Nature.

8. Lee A (2020) Wuhan novel coronavirus (COVID-19): why global control is challenging? Public Health 179: A1-A2.

9. Holshue ML, De Bolt C, Lindquist S, Lofy KH, Wiesman J, et al. (2020) V.C.I.T. Washington State -nCo, First Case of 2019 Novel Coronavirus in the United States. N Engl J Med.

10. Yoo H, Oh J, Park C (2020) Characteristics of fever and response to antipyretic therapy in military personnel with adenovirus-positive community-acquired pneumonia. Mil Med Res 7: 6 .

11.Wang D, Hu B, Hu C, Zhu F, Liu X, et al. (2020) Clinical Characteristics of 138 Hospitalized Patients With 2019 Novel Coronavirus-Infected Pneumonia in Wuhan. China. JAMA.

12. Jernigan DB, Team CCR (2020) Update: Public Health Response to the Coronavirus Disease 2019 Outbreak - United States, February 24, 2020. MMWR Morb Mortal Wkly Rep 69: 216-219.

13. Youmans AJ, Harwood J (2020) Gross and Histopathological Findings in the First Reported Vaping-Induced Lung Injury Death in the United States. Am J Forensic Med Pathol 41: 1-4.

14. Albarello F, Pianura E, Di Stefano F, Cristofaro M, Petrone A, et al. (2020) 2019-novel Coronavirus severe adult respiratory distress syndrome in two cases in Italy: An uncommon radiological presentation. Int J Infect Dis

15. Carinci F (2020) Covid-19: preparedness, decentralisation, and the hunt for patient zero BMJ 368: 799. 
16. Watkins J (2020) Preventing a covid-19 pandemic. BMJ 368: m810.

17. Sohrabi C, Alsafi Z, O’Neill N, Khan M, Kerwan A, et al. (2020) World Health Organization declares Global Emergency: A review of the 2019 Novel Coronavirus (COVID-19). Int J Surg.

18. Xu J, Zhao S, Teng T, Abdalla AE, Zhu W, et al.(2020) Systematic Comparison of Two Animal-to-Human Transmitted Human Coronaviruses: SARSCoV-2 and SARS-CoV. Viruses 12.

19. Xu Z, Shi L, Wang Y, Zhang J, Huang L, et al. (2020) Pathological findings of COVID-19 associated with acute respiratory distress syndrome. Lancet Respir Med 8(4): 420-422.

20. Xu YH, Dong JD, An WM, Lv XY, Yin XP, et al. (2020) Clinical and computed tomographic imaging features of Novel Coronavirus Pneumonia caused by SARS-CoV-2. J Infect 80(4): 394-400.

21. Wu J, Liu J, Zhao X, Liu C, Wang W, et al. (2020) Clinical Characteristics of Imported Cases of COVID-19 in Jiangsu Province: A Multicenter Descriptive Study. Clin Infect Dis.

ISSN: $2574-1241$

DOI: $10.26717 /$ BJSTR.2020.27.004459

Luhuan Yang, Yunhong Lei. Biomed J Sci \& Tech Res

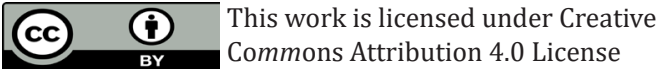

Submission Link: https://biomedres.us/submit-manuscript.php
22. Guan WJ, Ni ZY, Hu Y, Liang WH, Ou CQ et al. (2020) China Medical Treatment Expert Group for, Clinical Characteristics of Coronavirus Disease 2019 in China. N Engl J Med.

23. Zhang L, Liu Y (2020) Potential Interventions for Novel Coronavirus in China: A Systematic Review.J Med Virol 92(5): 479-490.

24. Ma XL, Chen Z, Zhu JJ, Shen XX, Wu MY, et al. (2020) Management strategies of neonatal jaundice during the coronavirus disease 2019 outbreak. World J Pediatr.

25. Wax RS, Christian MD (2020) Practical recommendations for critical care and anesthesiology teams caring for novel coronavirus (2019$\mathrm{nCoV}$ ) patients. Can J Anaesth 12: 1-9.

26. Peeri NC, Shrestha N, Rahman MS, Zaki R, Tan Z, et al. (2020) The SARS, MERS and novel coronavirus (COVID-19) epidemics, the newest and biggest global health threats: what lessons have we learned? Int J Epidemiol.

$\begin{array}{ll}\text { BIOMEDICAL } & \text { Assets of Publishing with us } \\ \text { RESEARCHES } & \text { - Global archiving of articles } \\ \text { - Immediate, unrestricted online access }\end{array}$

